\title{
Creating and disseminating a home-based cardiac rehabilitation program: experience from the Veterans Health Administration
}

\author{
Bonnie J. Wakefield ${ }^{1,2^{*}}$ (D, Kariann Drwal ${ }^{1}$, Monica Paez ${ }^{2}$, Sara Grover ${ }^{1}$, Carrie Franciscus ${ }^{2}$, \\ Heather Schacht Reisinger ${ }^{1,2,3}$, Peter J. Kaboli ${ }^{1,2,3}$ and Ramzi El Accaoui ${ }^{3}$
}

\begin{abstract}
Background: Cardiac rehabilitation (CR) programs provide significant benefit for people with cardiovascular disease. Despite these benefits, such services are not universally available. We designed and evaluated a national home-based CR (HBCR) program in the Veterans Health Administration (VHA). The primary aim of the study was to examine barriers and facilitators associated with site-level implementation of HBCR.

Methods: This study used a convergent parallel mixed-methods design with qualitative data to analyze the process of implementation, quantitative data to determine low and high uptake of the HBCR program, and the integration of the two to determine which facilitators and barriers were associated with adoption. Data were drawn from 16 VHA facilities, and included semi-structured interviews with multiple stakeholders, document analysis, and quantitative analysis of CR program attendance codes. Qualitative data were analyzed using the Consolidated Framework for Implementation Research codes including three years of document analysis and 22 interviews.

Results: Comparing high and low uptake programs, readiness for implementation (leadership engagement, available resources, and access to knowledge and information), planning, and engaging champions and opinion leaders were key to success. High uptake sites were more likely to seek information from the external facilitator, compared to low uptake sites. There were few adaptations to the design of the program at individual sites.

Conclusion: Consistent and supportive leadership, both clinical and administrative, are critical elements to getting HBCR programs up and running and sustaining programs over time. All sites in this study had external funding to develop their program, but high adopters both made better use of those resources and were able to leverage existing resources in the setting. These data will inform broader policy regarding use of HBCR services.
\end{abstract}

Keywords: Home based cardiac rehabilitation, Veterans affairs medical centers, Program implementation

\section{Background}

Cardiac rehabilitation (CR) programs provide significant benefit for people with cardiovascular disease [1-3]. Despite these benefits, such services are not universally available. Hospitals with limited resources, including many Veterans Affairs medical centers (VAMC) with a high percentage of

\footnotetext{
*Correspondence: wakefieldb@missouri.edu

'VA Office of Rural Health (ORH), Veterans Rural Health Resource

Center-Central Region, lowa City VA Healthcare System, 601 Highway 6 West, Mailstop 152, lowa City, IA 52246-2208, USA

${ }^{2}$ The Comprehensive Access and Delivery Research and Evaluation (CADRE) Center at the lowa City VA Healthcare System, 601 Highway 6 West, Mailstop 152, lowa City, IA 52246-2208, USA

Full list of author information is available at the end of the article
}

rural patients, do not offer on-site CR programs. In the Veterans Health Administration (VHA), only $28 \%$ of VAMCs (35/124) have an on-site CR program. Of 47,051 CReligible VHA patients (i.e., hospitalized for myocardial infarction (MI), percutaneous coronary interventions (PCI), or coronary artery bypass graft (CABG) surgery in the VHA nationally from 2006 to 2011) only 8.4\% participated in at least one session of $\mathrm{CR}$ in the 12-month posthospitalization period. However, Veterans are significantly more likely to participate in CR if they are hospitalized at a facility with an on-site program $(p<0.001)$ [4]. VHA has established a mechanism to ensure veterans have access to $\mathrm{CR}$ through non-VHA care contracted services at private

(c) The Author(s). 2019 Open Access This article is distributed under the terms of the Creative Commons Attribution 4.0 International License (http://creativecommons.org/licenses/by/4.0/), which permits unrestricted use, distribution, and reproduction in any medium, provided you give appropriate credit to the original author(s) and the source, provide a link to the Creative Commons license, and indicate if changes were made. The Creative Commons Public Domain Dedication waiver (http://creativecommons.org/publicdomain/zero/1.0/) applies to the data made available in this article, unless otherwise stated. 
sector hospitals. However, even these contracted programs are not available in all areas and thus create a considerable travel burden for Veterans who live at distance from program sites. Veterans often have a co-pay for non-VHA programs, increasing their financial burden. Other barriers for Veterans, found also in the private sector $[5,6]$, include need for a driver because of comorbid conditions, time away from work, or being the primary caregiver to children or ill family members.

To address access issues and low attendance rates at onsite CR programs, investigators have evaluated home based CR (HBCR) programs. Differences in patient outcomes between home and on-site CR programs are minimal for risk factor modification, mortality, quality of life, clinical events, and costs [7-11]. However, unknown is whether patients, providers, and organizations would willingly adopt this approach in practice. For instance, anecdotally providers often cite patient safety concerns about use of HBCR programs.

Given the evidence of the efficacy of CR, the effectiveness of HBCR programs, and access limitations to onsite programs, we developed, implemented, and evaluated a 12-week telephone/video-delivered HBCR program at the Iowa City Veterans Affairs Health Care System (ICVA). The program was structured to parallel on-site programs, spanning over 12 weeks. It provides patients with exercise prescription, education about their disease, medication compliance and heart healthy diet, assistance with tobacco cessation and psychosocial support. Program staff also relay any concerns or issues directly to the patient's primary physician or cardiologist. Standardized clinic names and codes and note templates were developed in order to standardize documentation and facilitate retrieval of data for evaluation (Fig. 1).

In our initial evaluation, Veterans were offered a choice of HBCR or non-VHA center-based CR. More Veterans chose the HBCR program, patient outcomes were comparable in non-VA CR and $\mathrm{HBCR}$, and a significantly greater number of sessions were completed in the $\mathrm{HBCR}$ $\mathrm{arm}$. There were no reported adverse events in the HCBR population [8]. Following the initial pilot, an external facilitation approach has been used to disseminate the HBCR model to multiple VA sites across the country.

The primary aim of the study reported here was to examine factors associated with site-level implementation of HBCR. Specifically, we report barriers and facilitators associated with adoption of HBCR in high vs. low uptake HBCR programs.

\section{Methods \\ Design}

This study used a convergent parallel mixed-methods design [12] with qualitative data to analyze the process of implementation, quantitative data to determine low and high uptake of the HBCR program, and the integration of the two to determine which facilitators and barriers were associated with adoption. The ICVA and University of Iowa Institutional Review Board approved the study. Interview participants provided informed consent.

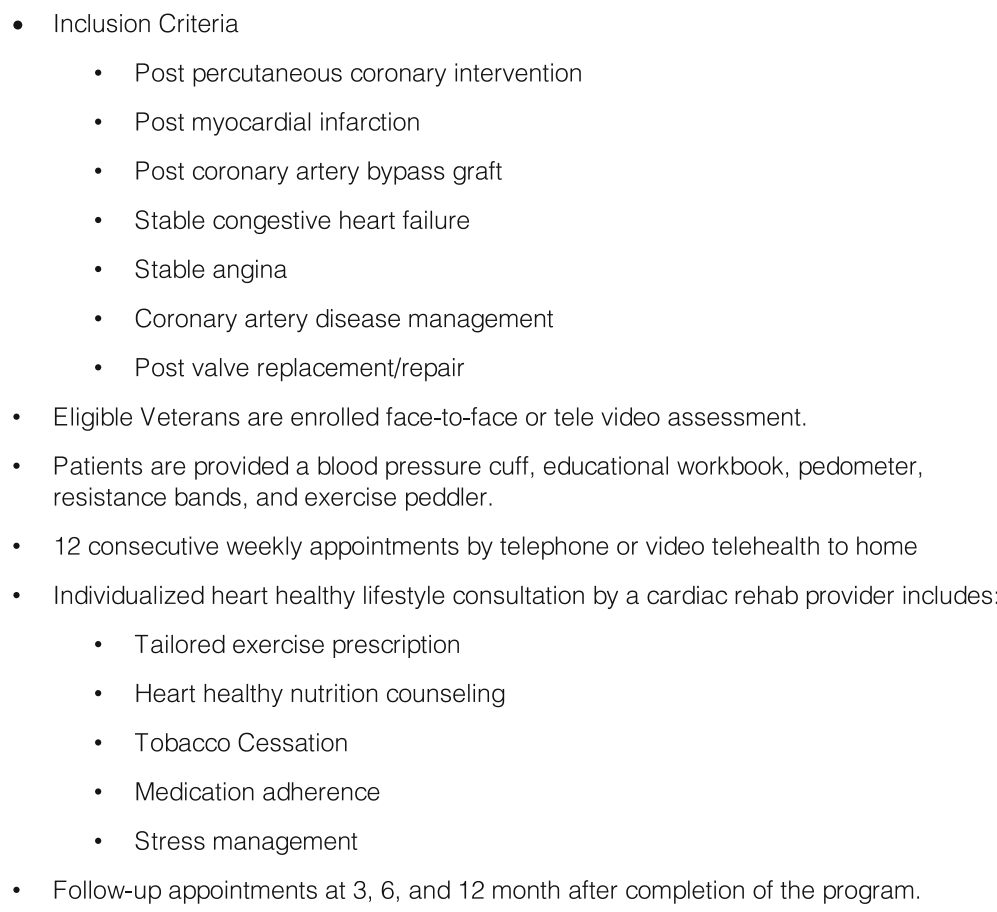

- Follow-up appointments at 3,6, and 12 month after completion of the program.

Fig. 1 Components of the Home-Based Cardiac Rehabilitation Program 


\section{Intervention}

An external facilitation approach $[13,14]$ was used to disseminate the HBCR program to other VAMCs interested in implementing the model. Interested sites completed a detailed application to become a HBCR site. Each approved site received the HBCR tool kit materials, initial training, monthly mentoring calls, SharePoint site access, and ongoing consultation from the Iowa City VA HBCR staff.

\section{Study framework}

We incorporated the Consolidated Framework for Implementation Research (CFIR) framework in this study [15]. The CFIR framework has been used in multiple implementation studies [16-18]. The framework includes 5 domains with associated constructs.

\section{Sample and data collection}

Sixteen VAMCs participated in implementation over a 3year period. We used documents from interaction with the sites to reflect the day-to-day implementation activities, barriers encountered, and discussion of potential solutions. Minutes were maintained for all monthly meetings, and all emails sent to or received by the external facilitator about the HBCR program were saved in electronic files [19].

To obtain a broader range of perceptions related to workflow processes, barriers, and facilitators to HBCR implementation at the organizational level, semi-structured telephone interviews were conducted with local VHA clinical leadership, providers, and program staff at a sample of nine geographically diverse HBCR sites across a range of uptake. An interview guide was developed using questions derived from the suggested interview questions provided by the CFIR wiki site (cfirguide.org). Questions addressed individual, organizational, cultural, and social factors that may influence support for HBCR. Site facilitators identified potential interviewees. Interviews lasted 8 to $92 \mathrm{~min}$ (average of 32).

To categorize high versus low uptake sites, patient participation data were obtained through the VHA Informatics and Computing Infrastructure (VINCI), including VHA inpatient and outpatient encounter files and Purchased Care files. National VHA files were used to identify all patients with an inpatient diagnosis of acute MI, undergoing PCI, or CABG surgery, the primary indications we used for the HBCR program. To assess CR participation following these qualifying events, we estimated the number of unique patients at each participating site who had an event in the first full fiscal year after the site entered into the study and who underwent one or more CR sessions at or paid for by the same site within 12 months after the qualifying event. Participation was categorized by 1) no participation, or attendance at one or more of the following: 2) VHA on-site CR programs; 3) non-VHA onsite CR programs; or 4) VHA home -based CR program.

\section{Data analysis}

All textual data were uploaded in MAXQDA, a qualitative software program for data management and analysis. The unit of analysis was the organizational level. Qualitative data were analyzed using the CFIR coding framework modeled on prior evaluations. A priori, we made the decision to use all CFIR domains except Domain IV. Characteristics of Individuals as this implementation was focused on the organizational level. We added an additional category under External Setting (Networks \& Communications, similar to Networks and Communication under Inner Setting) to describe communication occurring with outside organizations that may include other VHA facilities. Other modifications were made to the CFIR structure during the coding process. Under Inner Setting we created three sub-codes for this category: Program Characteristics, Organization Characteristics and Program Development. Under "External Change Agent" added "advice codes" to reflect advice sought and provided to implementation sites by the external facilitator. To ensure reliability in data coding, investigators coded the same emails/meeting minute transcripts and then met to examine the extent to which codes overlapped or diverged. The consensus approach was used to determine the final codes for analysis. Coding of interview transcripts was conducted in a similar fashion. Once initial coding was complete, data were then scored according to the influence of each CFIR category on implementation success $[17,20]$ using a modified scoring system where a score of 1 meant that the topic had a negative influence on implementation, 2 meant a neutral influence (neither positive nor negative), and 3 meant the topic had a positive influence.

\section{Results}

The 16 HBCR implementation sites ranged from small rural facilities to urban tertiary care centers (Table 1). Overall, the team coded three years of documents, including 37 monthly meeting minutes and 743 email communications. For interview data, 22 telephone interviews were conducted with 10 local facilitators, 7 site physicians, and 5 local staff associated with the program (e.g., physical therapy manager) at 9 program sites. Combined this included 6205 individual coded segments: $n=$ 2829 (46\%) from emails and meeting minutes (excluding the advice segments); $n=1525$ (25\%) from interviews; and $n=1851$ (30\%) advice from external facilitator found in emails and meeting minutes.

Facilities were grouped into high $(n=7)$, medium ( $n=$ $4)$, and low $(n=5)$ adoption facilities using natural cut points in the data (rate of HBCR participants following a qualifying event), HBCR participation (non- qualifying events). Table 1 indicates the number of patients at each site with qualifying events who attended center-based $\mathrm{CR}$ (VHA-based or private sector), and the number with 
Table 1 Participating Sites

\begin{tabular}{|c|c|c|c|c|c|c|c|}
\hline Site ID & $\begin{array}{l}\text { Overall Enrollment } \\
\text { at site }\end{array}$ & $\begin{array}{l}\text { Qualifying } \\
\text { Events }^{2}\end{array}$ & $\begin{array}{l}\text { Center } \\
\text { Based (N) }\end{array}$ & $\begin{array}{l}\% \text { attend } \\
\text { Center Based }\end{array}$ & $\begin{array}{l}\text { VHA home-based with } \\
\text { Qualifying Event }(\mathrm{N})\end{array}$ & $\begin{array}{l}\% \text { attend } \\
\text { Home Based }\end{array}$ & $\begin{array}{l}\text { Home Based, no documented } \\
\text { Qualifying Event }(\mathrm{N})\end{array}$ \\
\hline \multicolumn{8}{|c|}{ Low Adopter } \\
\hline 5 & 27,638 & 6 & 0 & $0.0 \%$ & 0 & $0 \%$ & 0 \\
\hline 13 & 76,697 & 338 & 20 & $5.9 \%$ & 0 & $0 \%$ & 0 \\
\hline 10 & 56,001 & 2 & 0 & $0.0 \%$ & 0 & $0 \%$ & 0 \\
\hline $6^{3,5}$ & 85,253 & 215 & 11 & $5.1 \%$ & 16 & $7 \%$ & 28 \\
\hline $8^{*}$ & 45,746 & 8 & 0 & $0.0 \%$ & 0 & $0 \%$ & 1 \\
\hline \multicolumn{8}{|c|}{ Medium Adopter } \\
\hline 11 & 62,210 & 211 & 21 & $10.0 \%$ & 0 & $0 \%$ & 26 \\
\hline 18 & 84,196 & 128 & 14 & $10.9 \%$ & 4 & $3 \%$ & 13 \\
\hline $1^{4,5}$ & 32,309 & 1 & 0 & $0.0 \%$ & 0 & $0 \%$ & 46 \\
\hline $17^{*}$ & 116,980 & 143 & 0 & $0.0 \%$ & 0 & $0 \%$ & 30 \\
\hline \multicolumn{8}{|c|}{ High Adopter } \\
\hline $12^{5}$ & 46,163 & 257 & 5 & $1.9 \%$ & 14 & $5 \%$ & 54 \\
\hline $16^{5}$ & 104,180 & 438 & 1 & $0.2 \%$ & 19 & $4 \%$ & 44 \\
\hline 3 & 25,219 & 50 & 0 & $0.0 \%$ & 5 & $10 \%$ & 39 \\
\hline $2^{5}$ & 73,404 & 178 & 2 & $1.1 \%$ & 12 & $7 \%$ & 60 \\
\hline $9^{5}$ & 55,281 & 325 & 40 & $12.3 \%$ & 94 & $29 \%$ & 158 \\
\hline $7^{5}$ & 169,809 & 485 & 1 & $0.2 \%$ & 60 & $12 \%$ & 228 \\
\hline 4 & 62,463 & 393 & 148 & $37.7 \%$ & 34 & $9 \%$ & 47 \\
\hline
\end{tabular}

${ }^{1}$ refers to the number of Veterans who have enrolled for care at each site

${ }^{2} \#$ with myocardial infarction, percutaneous coronary intervention, coronary artery bypass graft; patients may have had care at more than one VA, so numbers are unique to each VA only; patients could also have had events/CR across multiple fiscal years and are counted only once per fiscal year; a qualifying event occurred no more than 3 months prior to the site's start date; some patients had more than one qualifying event; CR must occur within 365 days after a qualifying event

${ }^{3}$ site 6 - site dropped out of program

${ }^{4}$ site 1 - outpatient only setting

${ }^{5}$ Interview sites

qualifying events who attended HBCR. The last column in Table 1 indicates the number of patients who participated in HBCR for whom no qualifying event was documented in the national data base, e.g., patients with stable heart failure could be referred to the program. Qualifying events were determined for each site, however patients may have had care at more than one VA, so numbers are unique to each VA only. A qualifying event was counted if it occurred no more than 3 months prior to the site's start date; CR occurring up to 365 days after a qualifying event were included. We defined "adoption" as continued participation in the program past the first year [17]. We used the influence ratings to provide an estimate of the magnitude (positive or negative) of each construct. Only high and low uptake sites are included in this analysis.

The prominent difference between high and low uptake facilities influence scores was in Readiness for Implementation, which includes leadership engagement, available resources, and access to knowledge and information and Process factors, including planning, champions and opinion leaders (Table 2).

\section{Leadership engagement}

In the high uptake organizations, clinical leadership was evident. Although local clinical leadership was strong in high uptake facilities, less support was displayed in organizational leadership roles. In contrast, low uptake sites struggled obtaining leadership support.

\section{Available resources}

In the high uptake group, the ability to get staff up and going efficiently facilitated implementation of the program. These facilities also had local organizational resources and collaborations available to complement program activities, such as active physical therapy departments. High uptake sites did encounter barriers with resources, e.g., finding space to conduct the program, but seemed to be able to address the barrier compared to low uptake sites. In fact, one site found the homebased program provided a solution to the lack of on-site space for a center based program. In contrast to the high uptake sites, low uptake sites seemed to have fewer organizational resources. 
Table 2 Differences between High and Low Adoption Programs ${ }^{1}$

\begin{tabular}{lll}
\hline & $\begin{array}{l}\text { High Adopters } \\
\text { Mean (SD) }\end{array}$ & $\begin{array}{l}\text { Low Adopters } \\
\text { Mean (SD) }\end{array}$ \\
\hline INNER SETTING & & \\
$\quad$ Readiness for implementation: & & $1.4(0.3)$ \\
$\quad$ Leadership engagement & $2.2(0,7)$ & $1.7(0.6)$ \\
Available resources & $2.4(0.3)$ & $2.1(0.5)$ \\
Access to knowledge & $3(0)$ & \\
PROCESS & & $2.3(0.2)$ \\
$\quad$ Planning & $2.9(0.1)$ & $2(0.7)$ \\
$\quad$ Engaging: Champions & $2.8(0.2)$ & $2(1.0)$ \\
$\quad$ Engaging: Opinion leaders & $2.8(0.2)$ &
\end{tabular}

${ }^{1}$ All differences at $p$-value $\leq 0.05$

${ }^{2} 1$ = negative influence; $2=$ neutral influence; $3=$ positive influence

\section{Access to knowledge and information}

High uptake sites were able to take advantage of the knowledge provided by the program SharePoint and external facilitator staff. Low uptake sites had less information at the local level, and when information was available (as on the SharePoint site), using it presented challenges.

However, low uptake sites did express the helpfulness of the provided information, both from the initial training and information on the SharePoint.

Process factors, including Planning, champions and opinion leaders were also more prevalent at high adoption sites. High adoption sites engaged in active program planning. Although low adopters did spend time planning, the process was often much slower at these sites. Opinion leaders at high adopter sites were more engaged with the process of implementation. Low adopter sites encountered difficulty engaging opinion leaders.

Finally, high adopter sites typically had local champions to help move implementation forward. At high adoption sites, support from providers, particularly local cardiologists, was key in success. However, low adoption sites often exhibited changes in leadership (both clinical and administrative) that led to a lack of champions. For example, one site had a very supportive Chief of Staff, who initially championed the program. However, after he left, support was not provided.

The frequency of Advice codes was also different between high and low uptake sites. In the high uptake sites, requests for advice ranged from 18 to 35 per year (average 24/site/year). In low uptake sites, requests ranged from 9 to 24 per year (average 16/site/year).

\section{Discussion}

Comparing high and low uptake programs, readiness for implementation (leadership engagement, available resources, and access to knowledge and information), planning, and engaging champions and opinion leaders were key. Analysis of the external facilitator's emails also indicated that advice was frequently needed on funding, structural characteristics, using available resources, and access to knowledge and information. High uptake sites were also more likely to seek information from the facilitator, compared to low uptake sites.

There were few adaptations to the design of the program at individual sites. All sites used the same electronic medical record and patient program materials. The most common adaptation was the profession of the local site facilitator, e.g., although the external facilitator was an exercise physiologist, some sites chose to use registered nurses or physical therapists. Site facilitators and interview participants were very positive about the design of the program, the helpfulness of the external facilitator, and acknowledged that the program met patient needs for access to care. Because the VHA uses one EMR, sharing note templates and clinic codes across all sites facilitated standardized data entry formats and accessing clinic data for program uptake estimates. Thus, standardized data entry approaches and common clinic codes across the country will facilitate evaluation of data contained in the database.

Successful sites demonstrated both strong administrative and clinical leadership, particularly from cardiologists involved in program implementation. These physicians championed the program and communicated with hospital leadership about the importance of the program. Low uptake programs often exhibited inconsistent leadership, i.e., frequent changes in leadership, departure of a supportive physician leader who was then replaced by a less supportive or non-supportive leader. One low adopter site spent the first 10 months in planning activities, and had difficulty implementing the program.

High uptake sites appeared to both have greater available resources and were better able to leverage local resources to facilitate program implementation. Successful sites often used existing support staff such as nutritionists, and took advantage of available technology, i.e., secure messaging, to improve efficiency of weekly visits. While space was a potential barrier, high uptake sites developed workarounds to address the space problem. For example, at one site, the lack of space was addressed by allowing HBCR providers to work from home (telework) to implement the program.

All sites had access to the SharePoint site for program toolkit materials and were invited to on-site training. While all programs found these sources of information very helpful, low uptake sites had greater difficulty taking advantage of this information. Furthermore, high uptake sites were more likely to seek out additional sources of information, such as professional society websites, to augment program materials, as well as advice and information from the external facilitator. 
Since these data were collected, the national program has grown to 28 sites, including 9 spoke sites. Hub sites, typically larger sites, provide HBCR program services to patients enrolled at mostly smaller, rural (spoke) sites who do not have a large population of patients for a full HBCR program. A recent analysis of CR within the VHA found that Veterans hospitalized at a facility with a HBCR program were 3 to 4 times more likely to participate in HBCR relative to an on-site VA program or non-VA program respectively [21]. Our initial program evaluation found that Veterans preferred the HBCR program to on-site non-VA programs [8]. Further implementation is supported by national guidelines that recommend use of HBCR for low risk patients [9]. Unfortunately, participation rates in either center-based or HBCR in this population remained low, a well-documented problem in CR programs [22, 23].

There are limitations to the study. The study was conducted within VHA facilities limiting external validity. Outside the VHA, differences in electronic records, human resources, finance, organizational climate, and processes will require "ground up" design and implementation. We do not report clinical outcomes, including adverse events. Grouping of sites by adoption levels may be viewed as arbitrary. Document analysis data were not created for purposes of research and thus are not as rigorous as interviews or focus groups, and important factors may go unmentioned. Although HBCR is more accessible, our program had low referral and enrollment rates, which is a longstanding issue in cardiac rehabilitation programs [24-26]. Lastly, a major barrier to adoption of HBCR in the United States is lack of insurance coverage for this type of homebased program.

\section{Conclusions}

Understanding how each VAMC implemented HBCR in their network, the role of facilitation in guiding program development, and local adaptations to program operation provided insight into initial and sustained acceptance of HBCR among a variety of stakeholders. Like other implementation efforts [27, 28] consistent and supportive leadership, both clinical and administrative, are critical elements to getting programs up and running and sustaining programs over time. All sites in this study had external funding to develop their program, but high adopters both made better use of those resources and were able to leverage existing resources in the setting. Although we did not test this association, it is likely that leadership and available resources are linked to each other, leading to successful implementation.

Most program implementation in health care settings is driven by a "top-down" (push) approach. This study adds to the implementation literature by examining factors associated with implementation using a "bottom-up" (pull) approach. Thus, these data provide critical information for healthcare institutions to begin to close the gap in access to $\mathrm{CR}$ services for patients regardless of where they reside. These data will also inform broader policy regarding use of HBCR services.

\begin{abstract}
Abbreviations
CABG: Coronary artery bypass graft surgery; CFIR: Consolidated framework for implementation research; CR: Cardiac rehabilitation; HBCR: Home-based cardiac rehabilitation; ICVA: lowa City veterans affairs health care system; MI: Myocardial infarction; PCI: Percutaneous coronary interventions;

VAMC: Veterans affairs medical centers; VHA: Veterans health administration; VINCI: VHA informatics and computing infrastructure
\end{abstract}

\section{Acknowledgments}

Not applicable.

\section{Authors' contributions}

Program design and implementation: BJW, KD, SG, PJK, REL. Study design: BJW, HSR, CF, PJK. Data analysis: BJW, KD, MP, SG, CF. Manuscript writing/ review: BJW, KD, PJK, REL. All authors read and approved the final version of the manuscript.

\section{Funding}

The work reported here was supported by the Department of Veterans Affairs, Veterans Health Administration, Office of Rural Health, Veterans Rural Health Resource Center-Central Region, and the Health Services Research and Development Service through the Comprehensive Access and Delivery Research and Evaluation Center (CIN 13-412). The funding bodies did not participate in the design of the study; collection, analysis, or interpretation of the data; or writing the manuscript. The views expressed in this article are those of the authors and do not necessarily represent the views of the Department of Veterans Affairs. The authors report no conflict of interest regarding this study.

\section{Availability of data and materials}

The datasets used and/or analyzed during the current study are available from the corresponding author on reasonable request.

\section{Ethics approval and consent to participate}

The lowa City Veterans Affairs Health System and University of lowa Institutional Review Board approved the study. Interview participants provided verbal informed consent because all interviews were conducted via telephone; the lowa City Veterans Affairs Health System and University of lowa Institutional Review Board approved verbal consent.

Consent for publication

Not applicable.

\section{Competing interests}

The authors declare that they have no competing interests.

\section{Author details}

'VA Office of Rural Health (ORH), Veterans Rural Health Resource Center-Central Region, lowa City VA Healthcare System, 601 Highway 6 West, Mailstop 152, lowa City, IA 52246-2208, USA. ${ }^{2}$ The Comprehensive Access and Delivery Research and Evaluation (CADRE) Center at the lowa City VA Healthcare System, 601 Highway 6 West, Mailstop 152, lowa City, IA 52246-2208, USA. ${ }^{3}$ The Department of Internal Medicine, University of lowa Carver College of Medicine, lowa City, USA.

Received: 28 January 2019 Accepted: 16 October 2019

Published online: 06 November 2019

\section{References}

1. Hammill BG, Curtis LH, Schulman KA, Whellan DJ. Relationship between cardiac rehabilitation and long-term risks of death and myocardial infarction among elderly Medicare beneficiaries. Circulation. 2010;121(1):63-70.

2. Suaya JA, Stason WB, Ades PA, Normand SL, Shepard DS. Cardiac rehabilitation and survival in older coronary patients. J Am Coll Cardiol. 2009;54(1):25-33. 
3. Heran BS, Chen JM, Ebrahim S, et al. Exercise-based cardiac rehabilitation for coronary heart disease. Cochrane Database Syst Rev. 2011;7. https://doi.org/ 10.1002/14651858.CD001800.pub2.

4. Schopfer DW, Takemoto S, Allsup K, et al. Cardiac rehabilitation use among veterans with ischemic heart disease. JAMA Intern Med. 2014;174(10):16879. https://doi.org/10.1001/jamainternmed.2014.3441.

5. Daly J, Sindone AP, Thompson DR, Hancock K, Chang E, Davidson P. Barriers to participation in and adherence to cardiac rehabilitation programs: a critical literature review. Prog Cardiovasc Nurs. 2002;17(1):8-17.

6. Jackson L, Leclerc J, Erskine Y, Linden W. Getting the most out of cardiac rehabilitation: a review of referral and adherence predictors. Heart. 2005;91(1):10-4.

7. Jolly K, Taylor RS, Lip GYH, Stevens A. Home-based cardiac rehabilitation compared with Centre-based rehabilitation and usual care: a systematic review and meta-analysis. Int J Cardiol. 2006;111(3):343-51.

8. Wakefield B, Drwal K, Scherubel M, Klobucar T, Johnson S, Kaboli P. Feasibility and effectiveness of remote, telephone-based delivery of cardiac rehabilitation. Telemedicine e-Health. 2014;20(1):32-8. https://doi.org/10. 1089/tmj.2013.0079.

9. Smith SC, Benjamin EJ, Bonow RO, et al. AHA/ACCF secondary prevention and risk reduction therapy for patients with coronary and other atherosclerotic vascular disease: 2011 update: a guideline from the American Heart Association and American College of Cardiology Foundation. Circulation. 2011;124(22):2458-73. https://doi.org/10.1161/CIR. Ob013e318235eb4d.

10. Taylor RS, Dalal H, Jolly K, et al. Home-based versus centre-based cardiac rehabilitation. Cochrane Database Syst. Rev. 2015;2015(8) doi: https://doi. org/10.1002/14651858.CD007130.pub3.

11. Blair J, Corrigall H, Angus NJ, Thompson DR, Leslie S. Home versus hospitalbased cardiac rehabilitation: a systematic review. Rural Remote Health. 2011 11(2):1532 Available: www.rrh.org.au/journal/article/1532.

12. Creswell J, Plano-Clark V. Designing and conducting mixed methods research. 2nd ed. Los Angeles: Sage; 2011.

13. Kirchner JE, Parker LE, Bonner LM, Fickel JJ, Yano EM, Ritchie MJ. Roles of managers, frontline staff and local champions, in implementing quality improvement: Stakeholders' perspectives. J Eval Clin Pract. 2012;18(1):63-9. https://doi.org/10.1111/j.1365-2753.2010.01518x

14. Ritchie MJ, Parker LE, Edlund CN, Kirchner JE. Using implementation facilitation to foster clinical practice quality and adherence to evidence in challenged settings: A qualitative study. BMC Health Serv. Res. 2017;17(1). https://doi.org/10.1186/s12913-017-2217-0.

15. Damschroder $L$, Aron DC, Keith RE, Kirsh SR, Alexander JA, Lowery JC. Fostering implementation of health services research findings into practice: A consolidated framework for advancing implementation science. Implement. Sci. 2009;4(1). https://doi.org/10.1186/1748-5908-4-50.

16. Hadjistavropoulos HD, Nugent MM, Dirkse D, Pugh N. Implementation of internet-delivered cognitive behavior therapy within community mental health clinics: A process evaluation using the consolidated framework for implementation research. BMC Psychiatry. 2017;17(1). https://doi.org/10. 1186/s12888-017-1496-7.

17. Damschroder LJ, Lowery JC. Evaluation of a large-scale weight management program using the consolidated framework for implementation research (CFIR). Implement. Sci. 2013;8(1). https://doi.org/10.1186/1748-5908-8-51.

18. Kirk MA, Kelley C, Yankey N, Birken SA, Abadie B, Damschroder L. A systematic review of the use of the Consolidated Framework for Implementation Research. Implement. Sci. 2016;11(1). https://doi.org/10. 1186/s13012-016-0437-z

19. Bowen GA. Document analysis as a qualitative research method. Qual Res J. 2009;9(2):27-40. https://doi.org/10.3316/QRJ0902027.

20. Damschroder $L$, Hagedorn HJ. A guiding framework and approach for implementation research in substance use disorders treatment. Psychol Addict Behav. 2011;25(2):194-205. https://doi.org/10.1037/a0022284.

21. Schopfer DW, Krishnamurthi N, Shen H, Duvernoy CS, Forman DE, Whooley MA. Association of veterans health administration home-based programs with access to and participation in cardiac rehabilitation. JAMA Intern Med. 2018;178(5):715-7. https://doi.org/10.1001/jamainternmed.2017.8039.

22. Jones MC, Smith $\mathrm{K}$, Herber $\mathrm{O}$, White M, Steele F, Johnston DW. Intention beliefs and mood assessed using electronic diaries predicts attendance at cardiac rehabilitation: an observational study. Int J Nurs Stud. 2018;88:14352. https://doi.org/10.1016/j.jinurstu.2018.08.015.

23. Resurrección DM, Moreno-Peral P, Gómez-Herranz M, et al. Factors associated with non-participation in and dropout from cardiac rehabilitation programmes: a systematic review of prospective cohort studies. Eur J Cardiovasc Nurs. 2019;18(1):38-47. https://doi.org/10.1177/

1474515118783157

24. Benzer W. How to identify and fill in the gaps in cardiac rehabilitation referral? Eur J Prev Cardiol. 2019;26(2):135-7. https://doi.org/10.1177/ 2047487318811695

25. McCarthy CP, Murphy S, Cohen JA, et al. Underutilization of cardiac rehabilitation for type 2 myocardial infarction. J Am Coll Cardiol. 2019; 73(15):2005-7. https://doi.org/10.1016/j.jacc.2019.01.032.

26. Santiago de Araújo Pio C, Beckie TM, Varnfield M, et al. Promoting patient utilization of outpatient cardiac rehabilitation: A joint International Counci and Canadian Association of Cardiovascular Prevention and Rehabilitation position statement. International Journal of Cardiology. 2019. https://doi. org/10.1016/j.ijcard.2019.06.064.

27. Aarons GA, Ehrhart MG, Farahnak LR, Sklar M. Aligning leadership across systems and organizations to develop a strategic climate for evidencebased practice implementation. Annual Review of Public Health: Annual Reviews Inc. 2014:255-74. https://doi.org/10.1146/annurev-publhealth032013-182447.

28. Guerrero EG, Fenwick K, Kong Y. Advancing theory development: Exploring the leadership-climate relationship as a mechanism of the implementation of cultural competence. Implement. Sci. 2017;12(1). https://doi.org/10.1186/ s13012-017-0666-9.

\section{Publisher's Note}

Springer Nature remains neutral with regard to jurisdictional claims in published maps and institutional affiliations.
Ready to submit your research? Choose BMC and benefit from:

- fast, convenient online submission

- thorough peer review by experienced researchers in your field

- rapid publication on acceptance

- support for research data, including large and complex data types

- gold Open Access which fosters wider collaboration and increased citations

- maximum visibility for your research: over $100 \mathrm{M}$ website views per year

At $\mathrm{BMC}$, research is always in progress.

Learn more biomedcentral.com/submissions 